\title{
Immunohistochemical evaluation of HLA-G and FoxP3+ T regulatory cells in oral cavity and lower lip squamous cell carcinomas
}

\begin{abstract}
Amanda Katarinny Goes GONZAGA(a)
\end{abstract}
Hellen Bandeira de Pontes SANTOS(a)

Janaina Cristiana Oliveira CRISPIM(b)

Lélia Batista de SOUZA(a)

Gustavo Martelli PALOMINO(b)

(a) Universidade Federal do Rio Grande do Norte - UFRN, Department of Dentistry, Postgraduate Program in Oral Pathology, Natal, RN, Brazil.

(b) Universidade Federal do Rio Grande do Norte - UFRN, Department of Clinical Analysis and Toxicology, Natal, RN, Brazil.

Declaration of Interests: The authors certify that they have no commercial or associative interest that represents a conflict of interest in connection with the manuscript.

Corresponding Author:

Amanda Katarinny Goes Gonzaga

E-mail: amandaggonzaga@gmail.com

https://doi.org/10.1590/1807-3107bor-2019.vol33.0020

Submitted: April 14, 2018

Accepted for publication: November 27, 2018

Last revision: February 25, 2019
Abstract: Human Leukocyte Antigen G (HLA-G) is a molecule involved in the tumor immunosuppression and also in the generation of regulatory $\mathrm{T}$ (Treg) cells, thus leading to evasion to the immune system host, and consequently, contributing to tumor progression in several cancers. The aim of this study was to evaluate the immunoexpression of HLA-G by tumor cells and FoxP3+ Treg cells in 25 oral tongue squamous cell carcinomas (SCCs) and 25 lower lip SCCs and analyze their relationship with clinical parameters. HLA-G expression was higher in oral tongue SCCs than in lower lip SCCs. In oral tongue SCCs and lower lip SCCs, no association between HLA-G expression and clinical parameters (tumor size, lymph node status, distant metastasis, and clinical stage) was verified $(P>0.05)$. FoxP3+ Treg cells were detected along the tumor invasive front in all cases of oral tongue and lower lip SCCs. In oral tongue SCC cases, the number of Treg cells tended to be higher in smaller tumors, tumors without regional lymph node metastasis, and tumors in early clinical stages, but the difference was not statistically significant $(P>0.05)$. A significant positive correlation was found between the expression of HLA-G by neoplastic cells and Treg cells in lower lip SCCs $(p=0.008)$. Our findings suggest the involvement of HLA-G and Treg cells in the modulation of immune responses in oral tongue and lower lip SCCs. This interaction between HLA-G and Treg cells may represent an evasion mechanism in these malignancies.

Keywords: T-Lymphocytes, Regulatory; Immunohistochemistry.

\section{Introduction}

Oral cancer is evidently a public health problem, considered to be the sixth most frequent tumor worldwide and an important cause of morbidity and mortality. ${ }^{1,2}$ Despite constant therapeutic breakthroughs, the 5-year survival rate remains low and the prognosis is still poor. ${ }^{3}$

Although both innate and adaptive immune systems play a crucial role in immunosurveillance, mutated or genetically modified cells can develop numerous immunomodulatory strategies that allow them to evade or withstand antitumor immune responses. Knowingly, one of 
the immune escape mechanisms utilized by tumor cells is the expression of human leukocyte antigen G (HLA-G). $4,5,6$

HLA-G is a nonclassical major histocompatibility complex (MHC) molecule and it is located on the short arm of chromosome 6 at 6p21.31. It is characterized by limited polymorphism, expression restricted to some tissues, and alternative splicing that leads to the production of seven different isoforms - four membrane-bound (HLA-G1 to G4) and three soluble isoforms (HLA-G5 to G7). ${ }^{4,5}$

All HLA-G isoforms can have an inhibitory effect on the cytotoxicity mediated by natural killer (NK) cells, cytotoxic Tlymphocytes, and antigen-presenting cells (APC), which are essential for an effective antitumor immune response. ${ }^{4,5}$ Such inhibition occurs by direct interaction of HLA-G with inhibitory receptors KIR2DL4 (CD158d), ILT-2 (CD85j), and ILT-4 (CD85d). ${ }^{4,7,8}$

Given the inhibitory immunological properties of HLA-G, some studies have associated the expression of this molecule in neoplastic cells with an immune escape mechanism. Therefore, the immunohistochemical expression of HLA-G has been demonstrated in different types of malignancies, ${ }^{9,10}$ often associated with a worse prognosis. ${ }^{9,10,11}$

The HLA-G molecule has indirect tolerogenic roles by producing regulatory $\mathrm{T}$ cells (Treg) - cells that can inhibit other T cells. ${ }^{12,13}$ APCs such as dendritic cells that express IL-10 and HLA-G can not only induce anergy and loss of responsive capacity by $\mathrm{T}$ lymphocytes against antigen stimuli, but also induce the differentiation of naïve T CD4+ lymphocytes into Treg cells, thereby contributing to immune response suppression. ${ }^{14,15}$ Treg cells express the Forkhead box P3 (FoxP3) nuclear transcription factor, regarded as one of the most reliable markers for the identification of these cell types. ${ }^{10,16}$ Once formed, Treg cells induced by HLA-G become independent and perform their modulatory activity. A few studies have associated a larger amount of Treg cells in malignant neoplasms with antitumor immune response evasion and, consequently, with a worse prognosis. ${ }^{17,18}$

Investigations about the role of HLA-G in oral cancer microenvironment and its relationship with clinical parameters is still lacking in the literature ${ }^{6,11,19}$ and, to date, there have been no investigations into the relationship between HLA-G and FoxP3+ Treg cells in these tumors. Therefore, the aim of the present study was to assess HLA-G expression in tumor cells and in FoxP3+ Treg cells in oral tongue and lower lip squamous cell carcinomas (SCCs), tumors with different behaviors and prognoses, and to verify its relationship with clinical parameters.

\section{Methodology}

\section{Tissue samples}

The present study was approved by the Research Ethics Committee of the Liga Norte Riograndense Contra o Câncer (protocol 1.974.047). The surgical specimens were divided into two groups: 25 cases of oral tongue SCC and 25 cases of lower lip SCC. Cases that underwent chemo/radiotherapy prior to surgical treatment were excluded. Sections $(5 \mu \mathrm{m})$ were cut from paraffin-embedded tissue blocks, deparaffinized, and stained with hematoxylin and eosin for histological examination All cases were examined under a light microscope by two oral pathologists for confirmation of the diagnosis. Clinical information, such as sex, age, and clinical staging (TNM), were obtained from the patient records.

\section{Immunohistochemical analysis}

For immunohistochemical study, 3- $\mu$ m-thick sections were cut from paraffin-embedded tissue blocks, deparaffinized, and submitted to antigen retrieval with Trilogy solution (Cell Marque, CA, USA). Endogenous peroxidase activity was blocked with $\mathrm{H}_{2} \mathrm{O}_{2} \mathrm{~V} 10$ for 15 minutes at room temperature. After that, the specimens were washed under running water and incubated with protein block (Thermo Scientific, Runcorn, UK) for 5 minutes at room temperature. Samples were washed twice in 1\% Tween 20 in TRIS$\mathrm{HCl}$ (tris-hydroxymethyl-aminomethane, Sigma Chemical Co., St. Louis, MO, USA), at pH 7.4, being replaced twice at 5-minute intervals for incubation with anti-HLA-G (clone MEM-G9, Exbio, Prague, Czech Republic, 1:400, overnight) and anti-FOXP3 (clone H190, Santa Cruz Biotechnology, Dallas, Texas, USA, 1:150, overnight) primary antibodies. 
The amplification reaction was performed with ADVANCE ${ }^{\mathrm{TM}}$ visualization system (Dako North America Inc., Carpinteria, CA, USA), and the diaminobenzidine (Liquid DAB + Substrate, Dako North America Inc., Carpinteria, CA, USA) was used to visualize peroxidase activity. Finally, the sections were counterstained with Mayer's hematoxylin, dehydrated and coverslipped. Samples of trophoblasts were used as positive control for anti-HLA-G, whereas histological sections of tonsils were used as anti-FoxP3 positive control. As negative control, the antibodies were replaced with $1 \%$ bovine serum albumin (BSA) buffer solution.

\section{Analysis of the immunohistochemical profile}

HLA-G in tumor cells and in FoxP3+ Treg cells was analyzed by two blinded oral pathologists. All slides were scanned (Panoramic MIDI, 3DHISTECH Kft 29-33, Konkoly-Thege M. str.Budapest, Hungary) and the images were assessed using the Panoramic Viewer 1.15.2 (3DHISTECH Kft 29-33, Konkoly-Thege M. str.Budapest, Hungary) software, which allowed visualizing the specimen along its full length.

HLA-G expression in the tumor invasive front was assessed by adapting the method proposed by Gonçalves et al. ${ }^{6}$. Tumor cells that exhibited granular cytoplasmic brown staining were considered to be positive. By using a semiquantitative assessment, the cases were classified as 0 (no immunopositive cells), 1 ( $<50 \%$ of immunopositive cells), and 2 ( $\geq 50 \%$ of immunoreactive cells).

The analysis of FoxP3+ Treg cells was made by adapting the method used by Schwarz et al. ${ }^{20}$. First, five areas of highest anti-FoxP3 immunoreactivity were selected along the tumor invasive front at $100 \times$ magnification. Each of the areas was photographed at $400 \times$ using the Image $₫$ (Image Processing and Analysis in Java, National Institute of Mental Health, Bethesda, MD, USA) software, and the FoxP3 lymphocytes stained in each field were counted, regardless of the intensity of the brown staining. The obtained values in each field were summed, determining the total count of FoxP3+ lymphocytes; and, then, this number was used to calculate the mean number of Treg cells per case.

\section{Statistical analysis}

The results were submitted to statistical analysis using the IBM SPSS Statistics program (version 20.0; IBM Corp., Armonk, NY, USA). Descriptive statistics was used for characterization of the sample. The Fisher's exact test was used to determine possible association setween the HLA-G expression by tumor cells and clinical parameters. The distribution of FoxP3+ lymphocyte counts was evaluated using the Kolmogorov-Smirnov test, which showed absence of a normal distribution. Therefore, the nonparametric Mann-Whitney test was used to compare median Treg cell numbers according to the different clinical parameters analyzed. Spearman's correlation test was performed to determine possible correlations between HLA-G expression by tumor cells and FoxP3+ lymphocyte counts. A $P$ value $<0.05$ was considered significant for all tests.

\section{Results}

\section{Clinical analysis}

In oral tongue SCCs, nineteen (76\%) out of the 25 cases were diagnosed in men. Patient age ranged from 41 to 89 years, with a mean of $62.1 \pm 14.2$ years. With respect to tumor size/extent and regional lymph node metastasis, there was a higher frequency of cases classified as T2 $(n=9 ; 36 \%)$ and N0 $(n=18$; $72 \%)$. Distant metastases were detected in only 4 cases $(16 \%)$. The most frequent clinical stages were stage II $(n=9 ; 36 \%)$ and stage III $(n=7 ; 28 \%)$ (Table 1$)$.

Regarding the lower lip SCCs, sixteen (64\%) of the 25 cases studied were diagnosed in men and nine $(36 \%)$ in women. Patient age ranged from 42 to 88 years, with a mean of $64.2 \pm 13.9$ years. Most cases were classified as T1 (44\%) and N0 (80\%). Distant metastases were not identified. Regarding clinical stage, stage I (32\%) was the most frequent (Table 1).

\section{Immunohistochemical analysis}

Neoplastic cells expressing HLA-G exhibited cytoplasmic and membrane staining in oral tongue and lower lip SCCs (Figure 1A-B). For oral tongue SCCs, the majority of cases showed a high immunoexpression of HLA-G $(n=21,84 \%)$, while 
Table 1. Distribution of cases of oral tongue and lower lip squamous cell carcinoma according to clinical parameters, HLA-G expression by tumor cells and FoxP3 + lymphocytes.

\begin{tabular}{|c|c|c|}
\hline \multirow{3}{*}{ Parameters } & \multicolumn{2}{|c|}{ Site } \\
\hline & Oral tongue & Lower lip \\
\hline & n (\%) & n (\%) \\
\hline \multicolumn{3}{|l|}{ Gender } \\
\hline Male & $19(76.0)$ & $16(64.0)$ \\
\hline Female & $6(24.0)$ & $9(36.0)$ \\
\hline Age & $62.1 \pm 14.2$ & $64.2 \pm 13.9$ \\
\hline \multicolumn{3}{|l|}{ Tumor } \\
\hline $\mathrm{T} 1$ & $6(24.0)$ & $11(44.0)$ \\
\hline $\mathrm{T} 2$ & $9(36.0)$ & $6(24.0)$ \\
\hline T3 & $7(28.0)$ & $1(4.0)$ \\
\hline $\mathrm{T} 4$ & $3(12.0)$ & $0(0.0)$ \\
\hline Not informed & - & $7(28.0)$ \\
\hline \multicolumn{3}{|l|}{ Lymph node metastasis } \\
\hline No & $18(72.0)$ & $20(80.0)$ \\
\hline N1 & $0(0.0)$ & $4(16.0)$ \\
\hline N2 & $7(28.0)$ & $1(0.0)$ \\
\hline N3 & $0(0.0)$ & $0(0.0)$ \\
\hline \multicolumn{3}{|l|}{ Distant metastasis } \\
\hline MO & $21(84.0)$ & $25(100.0)$ \\
\hline M1 & $4(16.0)$ & $0(0.0)$ \\
\hline \multicolumn{3}{|l|}{ Clinical stage } \\
\hline Stage I & $6(24.0)$ & $8(32.0)$ \\
\hline Stage II & $9(36.0)$ & $6(24.0)$ \\
\hline Stage III & $7(28.0)$ & $3(12.0)$ \\
\hline Stage IV & $3(12.0)$ & $1(4.0)$ \\
\hline Not informed & - & $7(28.0)$ \\
\hline \multicolumn{3}{|l|}{ HLA-G expression by tumor cells } \\
\hline Low (0 - 49\%) & $4(16.0)$ & $15(60.0)$ \\
\hline High (50 - 100\%) & $21(84.0)$ & $10(40.0)$ \\
\hline Median of FoxP3 + lymphocytes & 18.4 & 19.8 \\
\hline
\end{tabular}

in lower lip SCC cases, most cases ( $\mathrm{n}=15,60 \%)$ revealed a low expression (Table 1).

For oral tongue SCC cases, the Fisher's exact test showed no significant association between the expression of HLA-G by tumor cells and tumor size/extent $(p=1.000)$, lymph node status $(p=0.081)$, distant metastasis $(p=0.527)$ or clinical stage $(p=0.267)$ (Table 2). Similarly, Fisher's exact test revealed no association between the HLA-G expression by tumor cells and the clinical parameters in lower lip SCC cases $(p>0.05)$ (Table 2).

FoxP3+ lymphocytes were detected along the tumor invasive front in all cases (Figure 1 C-D). In the 25 cases of oral tongue SCC, the mean numbers of Treg lymphocytes ranged from 2 to 64.6 (median: 18.4), while in lower lip cases, the mean numbers of Treg lymphocytes ranged from 0.8 to 54 (median: 19.8).

In oral tongue SCC cases, with respect to tumor size/extent, the median number of FoxP3+ lymphocytes was 26.4 (range: $3.2-64.6$ ) in tumors classified as T1 and 16.6 (range 2.0-63.4) in tumors classified as T2-T4, with no significant difference between groups $(p=0.161)$. Regarding regional lymph node metastasis, the median number of FoxP3+ lymphocytes was 20.2 (range: 2.0-64.6) in tumors without metastases and 14.1 (range: 5.2-46.0) in tumors with metastases. The nonparametric Mann-Whitney test revealed no statistically significant difference between groups $(p=0.244)$. The median number of FoxP3+ lymphocytes was 20.2 (range: 3.2-64.6) in early stages (I/ II) and 15.9 (range: 2.0-63.4) in advanced stages (III/ IV). This difference was not statistically significant between groups $(p=0.542)$ (Figure 2).

For lower lip SCC cases, regarding tumor size/extent, the median number of FoxP3+ Treg cells was 19.8 (range: $0.8-54.0$ ) in tumors classified as T1 and 26.4 (range 9.8-46.6) in tumors classified as T2-T4, with no significant difference between groups ( $p=0.441)$. With respect to regional lymph node metastasis, the median number of FoxP3+ lymphocytes was 19.8 (range: 3.4-54.0) in tumors without metastases and 16.8 (range: $0.8-37.0$ ) in tumors with metastases. The nonparametric Mann-Whitney test revealed no statistically significant difference between groups $(p=0.497)$. Analysis of FoxP3+ lymphocytes according to the clinical stage showed a median number of 19.80 (range: 9.8-46.6) in early stages (I/ II) and of 18.8 (range: $0.8-37.0$ ) in advanced stages (III/ IV). This difference was not statistically significant (nonparametric Mann-Whitney test, $\mathrm{p}=0.821)$ (Figure 2).

Spearman's correlation test revealed no significant correlation between the HLA-G immunoexpression by tumor cells and FoxP3+ lymphocytes in oral tongue 
Table 2. Distribution of cases of oral tongue SCC and lower lip SCC according to HLA-G expression by tumor cells and clinical parameters.

\begin{tabular}{|c|c|c|c|c|c|c|c|c|}
\hline \multirow{4}{*}{ Clinical parameters } & \multicolumn{8}{|c|}{ HLA-G } \\
\hline & \multicolumn{3}{|c|}{ Oral tongue } & \multirow{3}{*}{$p$-value } & \multicolumn{3}{|c|}{ Lower lip } & \multirow{3}{*}{$\mathrm{p}$-value } \\
\hline & Low & High & Total & & Low & High & Total & \\
\hline & $0-49 \%(\%)$ & $50-100(\%)$ & n (\%) & & $0-49 \%(\%)$ & $50-100(\%)$ & $n(\%)$ & \\
\hline \multicolumn{9}{|l|}{ Tumor size } \\
\hline $\mathrm{Tl}$ & 1 (16.7) & $5(83.3)$ & $6(100.0)$ & $1.000^{*}$ & 7 (63.6) & $4(36.4)$ & 11 (100.0) & $0.630^{*}$ \\
\hline $\mathrm{T} 2-\mathrm{T} 4$ & $3(15.8)$ & $16(84.2)$ & 19 (100.0) & & $3(42.9)$ & $4(57.1)$ & $7(100.0)$ & \\
\hline \multicolumn{9}{|l|}{ Nodal metastasis } \\
\hline No & $1(5.9)$ & $16(94.1)$ & $17(100.0)$ & $0.081^{*}$ & $12(60.0)$ & $8(40.0)$ & $20(100.0)$ & $1.000^{*}$ \\
\hline$N 1-N 3$ & $3(37.5)$ & $5(62.5)$ & $8(100.0)$ & & $3(60.0)$ & $2(40.0)$ & $5(100.0)$ & \\
\hline \multicolumn{9}{|l|}{ Distant metastasis } \\
\hline MO & $3(14.3)$ & $18(85.7)$ & $21(100.0)$ & $0.527^{*}$ & - & - & - & - \\
\hline M1 & $1(25.0)$ & $3(75.0)$ & $4(100.0)$ & & - & - & - & \\
\hline \multicolumn{9}{|l|}{ Stage } \\
\hline$I-\|$ & $1(6.7)$ & 14 (93.3) & $15(100.0)$ & $0.267^{*}$ & $8(61.5)$ & $5(38.5)$ & $44(100.0)$ & $1.000^{*}$ \\
\hline III - IV & $3(30.0)$ & $7(70.0)$ & $10(100.0)$ & & $2(50.0)$ & $2(50.0)$ & $4(100.0)$ & \\
\hline
\end{tabular}

*Fisher's exact test.
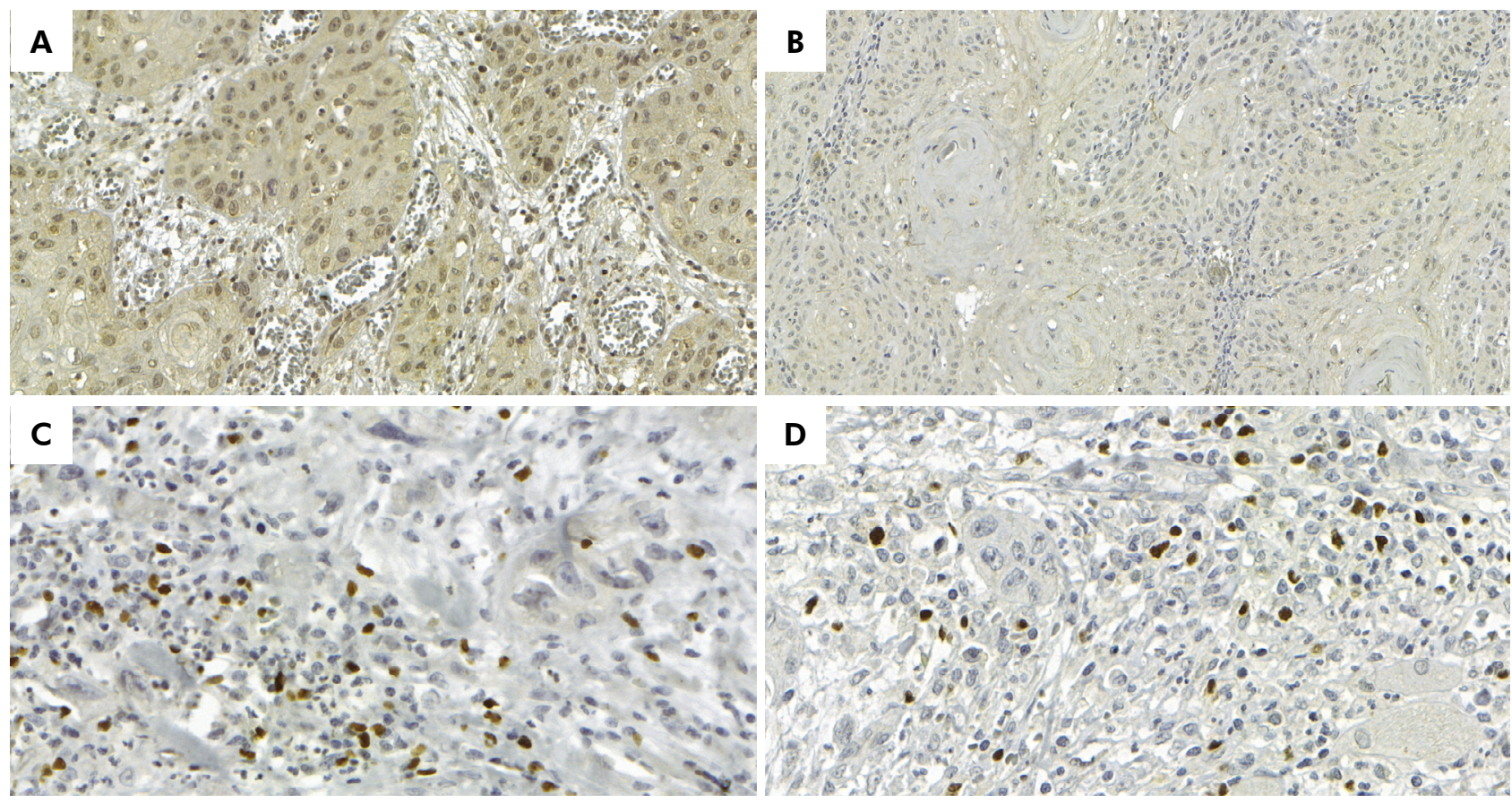

Figure 1. A) Diffuse and cytoplasmic HLA-G staining in tumor cells of an invasive oral tongue SCC. B) Low cytoplasmic expression of HLA-G in tumor cells of lower lip SCC. C) Regulatory T cells exhibiting strong nuclear expression of FoxP3 at the invasive front of oral tongue SCC. D) Regulatory T cells showing strong nuclear expression of FoxP3 at the invavise front of lower lip SCC. 

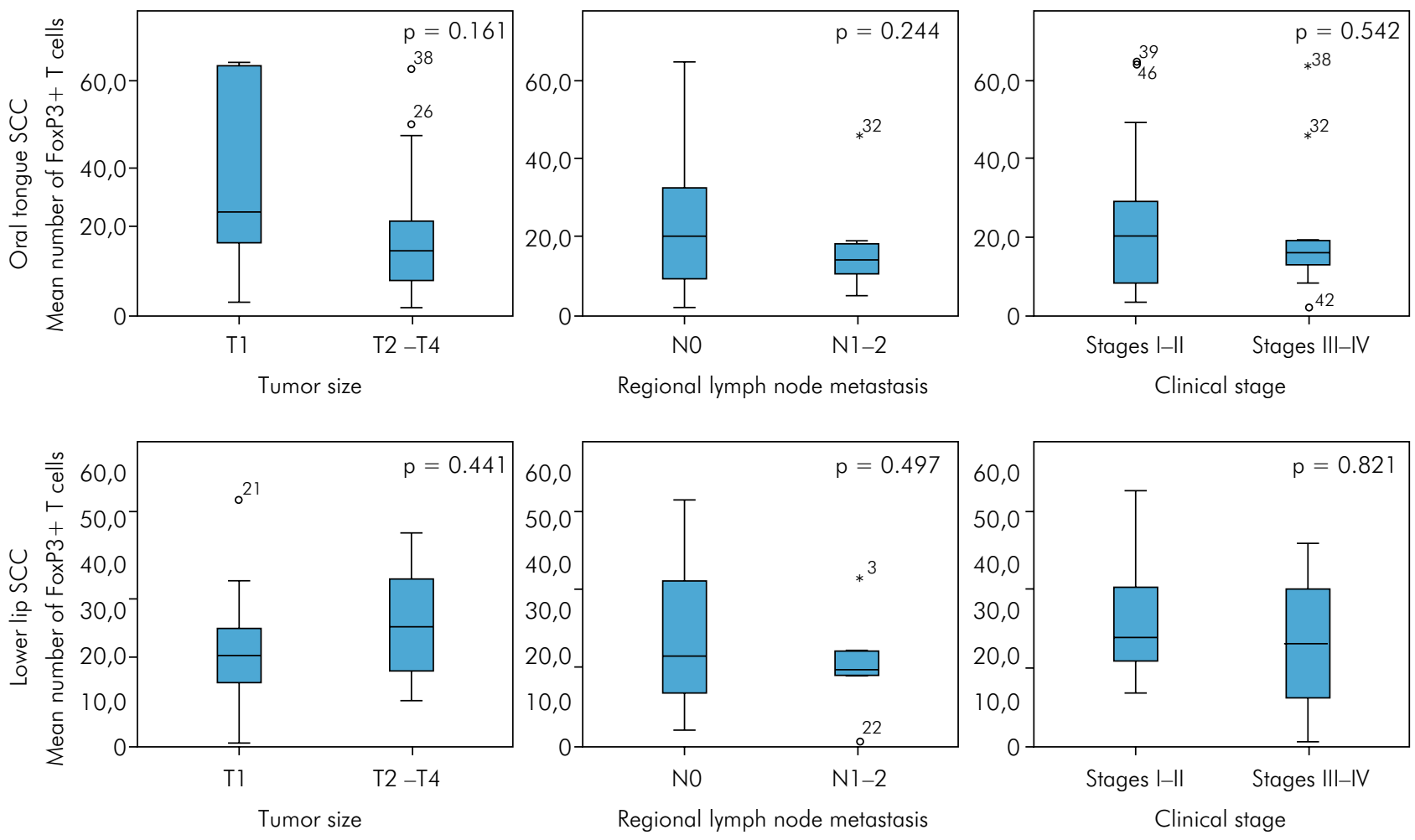

Figure 2. Box plot charts illustrating the number of regulatory T cells (FoxP3 ${ }^{+}$) in oral tongue SCC and lower lip SCC according to tumor size, regional lymph node metastasis, and clinical stage.

Table 3. Spearman's correlation between HLA-G immunoexpression by tumor cells and FoxP3 lymphocytes in oral tongue and lower lip squamous cell carcinomas.

\begin{tabular}{lccc}
\hline $\begin{array}{l}\text { HLA-G by tumor cells/FoxP3+ } \\
\text { lymphocytes }\end{array}$ & $n$ & $r$ & p-value \\
\hline Oral tongue SCC & 25 & 0.121 & 0.524 \\
Lower Lip SCC & 25 & 0.521 & 0.008 \\
\hline
\end{tabular}

SCCs $(p=0.524)$. However, a significant positive correlation was found between the expression of HLA-G by neoplastic cells and FoxP3 lymphocytes in lower lip SCCs $(p=0.008)$ (Table 3).

\section{Discussion}

Most types of cancer can develop different immunomodulatory strategies for evasion of antitumor response or resistance. Among the immune escape mechanisms used by tumor cells, HLA-G expression has been recently investigated in different types of human malignancies.,10,11,19 In the current literature, some studies have evaluated HLA-G immunoexpression in oral cancer. ${ }^{6,11,19,21}$ However, to our knowledge, this is the first study to compare HLA-G expression in oral tongue and of the lower lip SCCs, tumors that knowingly have different behaviors and prognoses.

Zancope et al. ${ }^{22}$ demonstrated that lip SCC often has a favorable prognosis if diagnosed early and has a more efficient antitumor immune response, with higher density of activated cytotoxic $\mathrm{T}$ lymphocytes and NK cells, when compared with intraoral SCC. These findings were strengthened by the results of the present study, in which there was a higher HLA-G expression in SCC of the oral tongue than in SCC of the lower lip, since the expression of this molecule can hinder the efficiency of immune cells. The higher expression of this molecule in oral tongue lesions may be attributed to their worse biological behavior when compared to lip lesions, which commonly have a good prognosis.

So far, only one study has assessed HLA-G expression in SCC of the lower lip. ${ }^{19}$ The authors observed higher HLA-G expression in premalignant 
lip lesions and in lip SCC than in the control group. The authors suggested that these lip lesions have an immunosuppressive microenvironment that favors the evasion of mutated keratinocytes in any stage of dysplasia. Despite the higher HLA-G expression in SCC of the lip than in the control group, the authors did not compare that expression with cases of intraoral SCC and, therefore, it was not possible to compare their results with the findings of the present study.

Gonçalves et al. ${ }^{6}$ assessed HLA-G expression in metastatic and nonmetastatic oral SCC. The authors observed a significantly higher HLA-G expression in metastatic oral SCC than in nonmetastatic cases and they also found that the high expression of this molecule was associated with lower survival rate, which indicates an unfavorable clinical prognosis. Their findings suggest the presence of HLA-G could be a tumor evasion mechanism, contributing to local immunosuppression and worse prognosis.

Studies conducted with other types of malignant neoplasms such as breast cancer, ${ }^{23}$ thyroid cancer, ${ }^{9}$ and rectal cancer ${ }^{10}$ demonstrated that HLA-G expression was significantly correlated with metastases and lower survival rates, highlighting the importance of the immunosuppressive activity of this molecule. However, our study did not reveal any significant association between HLA-G expression and the outcome of SCC cases, which may be attributed to the small sample size used.

The HLA-G molecule, in addition to having a direct tolerogenic response through its interaction with inhibitory receptors, may have an indirect and long-lasting action owing to differentiation into Treg cells. ${ }^{12,13,24}$ These cells are crucial mediators of self-tolerance and very important in the tumor microenvironment, expressing markers such as CD4, CD25 and FoxP3. ${ }^{18,25}$ Among these markers, FoxP3 is one of the most reliable markers for the identification of these cell types. ${ }^{10,16}$ Given the important effect of Treg cells on immune response suppression, large rates of these cells have been detected in the tumor microenvironment of different neoplasms, often associated with a more aggressive behavior. ${ }^{18,25}$

The clear role of Treg cells in oral carcinogenesis has not been fully established yet. While some studies suggest that the increase in the expression of FoxP3+ Treg cells may be related to a reduction in the immune response, leading to an unfavorable course of the disease, ${ }^{18,25}$ other studies have failed to demonstrate this relationship. ${ }^{26,27}$

In the present study, despite the lack of statistical significance, there was a larger number of FoxP3+ lymphocytes in smaller oral tongue SCCs, without lymph node metastasis, and in early stages. These findings are similar to those obtained by Bron et al. ${ }^{26}$ and Wolf et al. ${ }^{27}$. These authors underscore that the immunosuppressive activity of this subpopulation of $T$ cells could be particularly necessary in the early stages of carcinogenesis, in which tumor cells have higher immunogenicity and recruit a larger number of Treg cells in an attempt to suppress more efficient antitumor immune responses.

Few studies have been conducted about the expression of FoxP3+ Treg cells in lower lip SCCs. ${ }^{16,28}$ In line with our findings, these authors confirmed the presence of this subpopulation of T cells in the inflammatory infiltrate in the microenvironment of all SCC lesions of the lower lip assessed.

In the present study, there was a larger amount of FoxP3+ lymphocytes in larger SCCs of the lip in advanced clinical stages. These results are at odds with those of Cunha-Filho et al. ${ }^{16}$ which, to date, is the only study that has associated the expression of FoxP3+ Treg lymphocytes with clinicopathological parameters of SCCs of the lip. However, our findings are similar in terms of lymph node metastasis, as both studies detected a higher average number of FoxP3+ lymphocytes in nonmetastatic SCCs of the lip than in the metastatic cases, but this association was not significant. These observations also highlight the need for further investigations, with larger sample sizes and similar groups of comparison, to better establish the biological significance and the clinical importance HLA-G positivity in tumor cells and FoxP3+ lymphocytes in lower lip and oral tongueSCCs.

Although there was no significant correlation between HLA-G expression by tumor cells and FoxP3+ lymphocytes in SCCs of the oral tongue, a significant positive correlation was found between HLA-G expression by neoplastic cells and FoxP3+ lymphocytes in lower lip SCCs, suggesting that the combined expression of these two proteins in the 
tumor microenvironment of this malignancy may be related to a weak antitumor immune response.

\section{Conclusion}

Our results suggest the involvement of HLA-G and Treg cells in the modulation of immune mechanisms of microenvironment of oral tongue and lower lip SCCs. The higher HLA-G expression in SCC of the oral tongue when compared to lower lip SCC may be related to the worse biological behavior of tongue lesions. We believe the tumor evasion mechanism in oral cancer should be further investigated, since few previous studies categorically affirm that HLA-G expression is a strategy used by tumor cells to escape immunosurveillance and that this molecule could be a prognostic marker of this type of neoplasm in the future.

\section{References}

1. Casal D, Carmo L, Melancia T, Zagalo C, Cid O, Rosa-Santos J. Lip cancer: a 5-year review in a tertiary referral centre. J Plast Reconstr Aesthet Surg. 2010 Dec;63(12):2040-5. https://doi.org/10.1016/i.bjps.2009.12.022

2. Saito M, Kobyashi T, Takagi R, Saku T. Clinicopathological distinction of two categories of oral squamous cell carcinoma of the tongue: de novo vs. sequential types. Oral Med Pathol. 2012;16(3/4):81-8. https://doi.org/10.3353/omp.16.81

3. Zhou B, Chen WL, Wang YY, Lin ZY, Zhang DM, Fan S, et al. A role for cancer-associated fibroblasts in inducing the epithelial-to-mesenchymal transition in human tongue squamous cell carcinoma. J Oral Pathol Med. 2014 Sep;43(8):585-92. https://doi.org/10.1111/jop.12172

4. Rouas-Freiss N, Moreau P, Ferrone S, Carosella ED. HLA-G proteins in cancer: do they provide tumor cells with an escape mechanism? Cancer Res. 2005 Nov;65(22):10139-44. https://doi.org/10.1158/0008-5472.CAN-05-0097

5. Carosella ED, Moreau P, Lemaoult J, Rouas-Freiss N. HLA-G: from biology to clinical benefits. Trends Immunol. 2008 Mar;29(3):125-32. https://doi.org/10.1016/j.it.2007.11.005

6. Gonçalves AS, Wastowski IJ, Capeletti LR, Sacono NT, Cortez AP, Valadares MC, et al. The clinicopathologic significance of the expression of HLA-G in oral squamous cell carcinoma. Oral Surg Oral Med Oral Pathol Oral Radiol. 2014 Mar;117(3):361-8. https://doi.org/10.1016/i.0000.2013.12.001

7. Moreau P, Mouillot G, Rousseau P, Marcou C, Dausset J, Carosella ED. HLA-G gene repression is reversed by demethylation. Proc Natl Acad Sci USA. 2003 Feb;100(3):1191-6. https://doi.org/10.1073/pnas.0337539100

8. Mouillot G, Marcou C, Rousseau P, Rouas-Freiss N, Carosella ED, Moreau P. HLA-G gene activation in tumor cells involves cis-acting epigenetic changes. Int J Cancer. 2005 Mar;113(6):928-36. https://doi.org/10.1002/ijc.20682

9. Nunes LM, Ayres FM, Francescantonio IC, Saddi VA, Avelino MA, Alencar RC, et al. Association between the HLA-G molecule and lymph node metastasis in papillary thyroid cancer. Hum Immunol. 2013 Apr;74(4):447-51. https://doi.org/10.1016/i.humimm.2012.12.012

10. Reimers MS, Engels CC, Putter H, Morreau H, Liefers GJ, Velde CJ, et al. Prognostic value of HLA class I, HLA-E, HLA-G and Tregs in rectal cancer: a retrospective cohort study. BMC Cancer. 2014 Jul;14(1):486. https://doi.org/10.1186/1471-2407-14-486

11. Gonçalves AS, Arantes DA, Bernardes VF, Jaeger F, Silva JM, Silva TA, et al. Immunosuppressive mediators of oral squamous cell carcinoma in tumour samples and saliva. Hum Immunol. 2015 Jan;76(1):52-8. https://doi.org/10.1016/i.humimm.2014.11.002

12. Curigliano G, Criscitiello C, Gelao L, Goldhirsch A. Molecular pathways: human leukocyte antigen G (HLA-G). Clin Cancer Res. 2013 Oct;19(20):5564-71. https://doi.org/10.1158/1078-0432.CCR-12-3697

13. González A, Rebmann V, LeMaoult J, Horn PA, Carosella ED, Alegre E. The immunosuppressive molecule HLA-G and its clinical implications. Crit Rev Clin Lab Sci. 2012 May-Jun;49(3):63-84. https://doi.org/10.3109/10408363.2012.677947

14. Gregori S, Tomasoni D, Pacciani V, Scirpoli M, Battaglia M, Magnani CF, et al. Differentiation of type $1 \mathrm{~T}$ regulatory cells $(T r 1)$ by tolerogenic DC-10 requires the IL-10-dependent ILT4/HLA-G pathway. Blood. 2010 Aug;116(6):935-44. https://doi.org/10.1182/blood-2009-07-234872

15. LeMaoult J, Rouas-Freiss N, Carosella ED. HLA-G5 expression by trophoblast cells: the facts. Mol Hum Reprod. 2005 Oct;11(10):719-22. https://doi.org/10.1093/molehr/gah224

16. da Cunha FA, Aguiar MC, Souza LB, Pinto LP, Godoy GP, Alves PM, et al. Immunohistochemical analysis of FoxP3+ regulatory T cells in lower lip squamous cell carcinomas. Braz Oral Res. 2016 Dec;30(1):e130. https://doi.org/10.1590/1807-3107bor-2016.vol30.0130

17. Watanabe $Y$, Katou F, Ohtani H, Nakayama T, Yoshie O, Hashimoto K. Tumor-infiltrating lymphocytes, particularly the balance between CD8(+) T cells and CCR4(+) regulatory T cells, affect the survival of patients with oral squamous cell carcinoma. Oral Surg Oral Med Oral Pathol Oral Radiol Endod. 2010 May;109(5):744-52. https://doi.org/10.1016/j.tripleo.2009.12.015 
18. Gaur P, Qadir GA, Upadhyay S, Singh AK, Shukla NK, Das SN. Skewed immunological balance between Th17 (CD4(+)IL17A (+)) and Treg (CD4 (+)CD25 (+)FOXP3 (+)) cells in human oral squamous cell carcinoma. Cell Oncol (Dordr). 2012 Oct;35(5):335-43. https://doi.org/10.1007/s13402-012-0093-5

19. Gonçalves AS, Oliveira JP, Oliveira CF, Silva TA, Mendonça EF, Wastowski IJ, et al. Relevance of HLA-G, HLA-E and IL-10 expression in lip carcinogenesis. Hum Immunol. 2016 Sep;77(9):785-90. https://doi.org/10.1016/j.humimm.2015.12.001

20. Schwarz S, Butz M, Morsczeck C, Reichert TE, Driemel O. Increased number of CD25 FoxP3 regulatory T cells in oral squamous cell carcinomas detected by chromogenic immunohistochemical double staining. J Oral Pathol Med. 2008 Sep;37(8):485-9. https://doi.org/10.1111/j.1600-0714.2008.00641.x

21. Fregonezi PAG, Silva TGA, Simões RT, Moreau, P, Carosella ED, Kläy CPM, et al. Expression of nonclassical molecule human leukocyte antigen-G in oral lesions. Am J Otolaryngol. 2012;33(2):193-8. https://doi.org/10.1016/i.amjoto.2010.08.001

22. Zancope E, Costa NL, Junqueira-Kipnis AP, Valadares MC, Silva TA, Leles CR, et al. Differential infiltration of CD8+ and NK cells in lip and oral cavity squamous cell carcinoma. J Oral Pathol Med. 2010 Feb;39(2):162-7. https://doi.org/10.1111/i.1600-0714.2009.00792.x

23. Ramos CS, Gonçalves AS, Marinho LC, Gomes Avelino MA, Saddi VA, Lopes AC, et al. Analysis of HLA-G gene polymorphism and protein expression in invasive breast ductal carcinoma. Hum Immunol. 2014 Jul;75(7):667-72. https://doi.org/10.1016/i.humimm.2014.04.005

24. Feger U, Tolosa E, Huang YH, Waschbisch A, Biedermann T, Melms A, et al. HLA-G expression defines a novel regulatory T-cell subset present in human peripheral blood and sites of inflammation. Blood. 2007 Jul;110(2):568-77. https://doi.org/10.1182/blood-2006-11-057125

25. Hanakawa H, Orita Y, Sato Y, Takeuchi M, Ohno K, Gion Y, et al. Regulatory T-cell infiltration in tongue squamous cell carcinoma. Acta Otolaryngol. 2014 Aug;134(8):859-64. https://doi.org/10.3109/00016489.2014.918279

26. Bron L, Jandus C, Andrejevic-Blant S, Speiser DE, Monnier P, Romero P, et al. Prognostic value of arginase-II expression and regulatory T-cell infiltration in head and neck squamous cell carcinoma. Int J Cancer. 2013 Feb;132(3):E85-93. https://doi.org/10.1002/iic.27728

27. Wolf GT, Chepeha DB, Bellile E, Nguyen A, Thomas D, McHugh J; University of Michigan Head and Neck SPORE Program. Tumor infiltrating lymphocytes (TIL) and prognosis in oral cavity squamous carcinoma: a preliminary study. Oral Oncol. 2015 Jan;51(1):90-5. https://doi.org/10.1016/i.oraloncology.2014.09.006

28. Moreira G, Fulgêncio LB, DE Mendonça EF, Leles CR, Batista AC, Silva TA. T regulatory cell markers in oral squamous cell carcinoma: relationship with survival and tumor aggressiveness. Oncol Lett. 2010 Jan;1(1):127-32. https://doi.org/10.3892/0l_00000023 